\title{
MAKING ROOM FOR THE 3RS PRINCIPLES OF RESPONSIBLE ANIMAL USE IN ECOLOGY: POTENTIAL ISSUES IDENTIFIED THROUGH A PILOT SURVEY
}

\author{
Miriam A. Zemanova ${ }^{1,2,3, *}$ \\ ${ }^{1}$ Department of Philosophy, University of Basel, Steinengraben 5, 4051 Basel, Switzerland \\ Current affiliation: ${ }^{2}$ Centre for Compassionate Conservation, University of Technology Sydney, 15 \\ Broadway, Ultimo 2007 NSW, Australia \\ ${ }^{3}$ Animalfree Research, Postgasse 15, 3011 Bern, Switzerland \\ *Corresponding author: miriam.andela.zemanova@gmail.com
}

\begin{abstract}
.
Research on animals is one of the most controversial ethical issues in our society. The concern for animal welfare has been increasing in recent years and it is therefore imperative that any potential harm and distress to animals used in research is minimized. This could be achieved through the implementation of the so-called 3Rs principles for animal research (Replace, Reduce, Refine), which are now anchored in many legislations worldwide. In this scientific forum article, I comment on how the 3Rs might be useful specifically for ecological research on wildlife. While the main benefit of the 3 Rs principles is improved animal welfare, their implementation also provides opportunities for better science, saved costs, public support, and innovation. However, the awareness and implementation of the $3 R$ s, and attitudes about animal use in ecological research and education, have never been examined before. In order to close this gap, I conducted a pilot survey among ecologists working with wildlife. Even though the responses from 107 respondents from 23 countries are unlikely to represent the whole community of ecologists and should be, therefore, interpreted with caution, they provided several important insights. The responses from ecologists across different age classes and career stages revealed that lethal and invasive research methods might be prevalent when working with both invertebrate and vertebrate species, and that more than half of the respondents have never heard of the $3 R$ s principles for animal research. The reported lack of calculation of the minimum sample size and the widespread dissection classes as a part of education may also be of concern. Based on these findings, it is highly recommended to implement rigorous ethical and methodological standards for ecological practice and education and enforce the implementation of the 3 Rs principles in wildlife research.
\end{abstract}

\section{INTRODUCTION}

There is a consensus that ecological research and conservation efforts are necessary for the preservation of biodiversity (Cooke et al., 2017; Hone et al., 2018). In order to provide sound information for species management, ecologists need to assess, for example, how species interact (Zemanova et al., 2017a), the population densities of endangered animals (Molina et al., 2017), or gene flow among populations in a fragmented habitat due to land-use change (Zemanova et al., 2017b). While the impact of human activities such as forestry or agriculture on the welfare of wildlife has been acknowledged, the potential of ecological research itself to negatively affect the welfare of individual animals has been recognized less frequently (but see Fraser \& MacRae, 2011; Beausoleil, 2014; Costello et al., 2016; Zemanova, 2020).

This is despite the fact that ecological research can involve many practices that affect animal welfare - for instance, by causing stress through trapping (Harcourt et al., 2010), invasive marking (Powell \&
Proulx, 2003; MacRae et al., 2018), or invasive or lethal genetic sampling (Zemanova, 2019). Invasive methods, i.e., methods affecting the physical integrity of the animal (Lefort et al., 2019), are very likely to cause discomfort and even pain in animals with a discernible nervous system (Smith \& Lewin, 2009). Therefore, it is important to promote responsible animal use in all fields of life sciences (Jewell, 2013; Zemanova, 2020).

Probably the most often implemented guidance on responsible animal use in research and safeguarding animal welfare are the so-called 3Rs principles. These principles were proposed by Russell and Burch over sixty years ago (Russell \& Burch, 1959) and serve as a basis for research without the use of animals whenever possible (Replacement), with as few animals as possible (Reduction), and in which the animal's welfare is as good as possible (Refinement). The 3 Rs principles have been developed and traditionally applied in laboratory research, where the research focus is often on human health (Russell, 1995; Wurbel, 2017). This focus has been also 
reflected in the implementation strategies. For instance, one of the common approaches to implement the Replacement principle is to use the so-called organs-on-a-chip instead of a laboratory animal (Zhang et al., 2018). An organ-on-a-chip is a microfluidic structure containing human cell cultures that is capable of simulating the mechanics and physiology of an entire organ. This Replacement strategy would not be applicable to ecological research. For example, it is not possible to use cell cultures to determine the abundance or the population structure of deer. However, one obvious strategy to implement Replacement or Refinement in research on wildlife is the use of non-invasive research methods (Zemanova, 2019). Other approaches might include avoiding redundant measurements (de Jong, 2019), or improved study design (Zemanova, 2020).

There are multiple advantages associated with the implementation of the 3Rs principles in ecological research on wildlife (Fig. 1). The first obvious benefit is improved animal welfare. For instance, instead of using blood samples for genetic studies, we might use what animals leave behind - faeces, saliva, or urine (Zemanova, 2019). Capture can be extremely stressful for free-living animals, thus using a study design in which we do not even need to touch the animal avoids any potential complications such as capture myopathy or injury incurred from traps (Montané et al., 2002; Ponjoan et al., 2008). Moreover, scientific results might be invalid if they are affected by the stress or injury caused to the animal through invasive research methods (Hurst \& West, 2010). Implementing the 3Rs principles in wildlife research is therefore not only important for the well-being of animals under study, but it is also crucial to ensure robust science (Poole, 1997; Prescott \& Lidster, 2017).

The 3Rs principles can also serve as a practical ethical tool. Ecological studies and research on wildlife usually enjoy public support, as both scientists and the general public consider conservation of species - and the associated ecosystem services they provide - crucial for our long-term survival (IPBES, 2019). However, in a study by Bruskotter et al. (2019), the majority of respondents, identifying themselves as conservationists, support the idea that wildlife possess intrinsic value, and that people have an obligation to treat wildlife in an ethical way, not compromising their welfare. Consequently, research that has a high potential of harming the animal might be encountered with public outrage (McMahon et al., 2007).
Nowadays, the 3 Rs principles are an integral part of many legislations worldwide (Blattner, 2014). For instance, within the European Union, the 3Rs are implemented in the EU Directive 63/2010. Its Article 13 prescribes the choice of research methods in the following way: "In choosing between procedures, those which to the greatest extent meet the following requirements should be selected: (a) use the minimum number of animals; (b) involve animals with the lowest capacity to experience pain, suffering, distress or lasting harm; (c) cause the least pain, suffering, distress or lasting harm; and are most likely to provide satisfactory results." Furthermore, anyone working with animals is required to undertake specific training (EU Directive 63/2010). Implementation of the 3Rs principles is therefore in many countries a legal requirement. Other benefits include the cost-effectiveness of some of the non-invasive research methods (Ford et al., 2017; Alldredge et al., 2019) and the development of innovative approaches to wildlife research (Kersey \& Dehnhard, 2014; Hodgson et al., 2018).

So far, only a few studies have documented the experience, knowledge, and adoption of the 3Rs principles among researchers (e.g., Pollo et al., 2004; Leenaars et al., 2009; Franco \& Olsson, 2014; Franco et al., 2018), and none of them focused on ecologists. Considering the potentially substantial impact of ecological research on animal welfare (Zemanova, 2020) and the benefits associated with the imple-

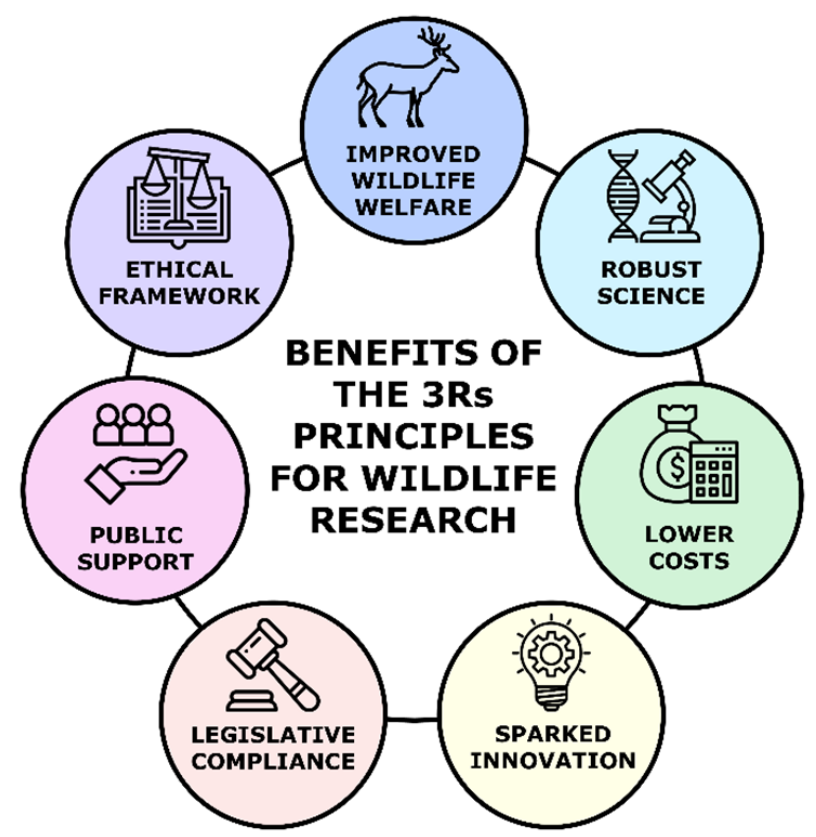

Figure 1: Benefits provided by the implementation of the 3Rs principles into ecological studies on wildlife. 
mentation of the 3Rs principles (Fig. 1), the present study aimed to explore the experience, attitudes, and knowledge regarding animal use and the 3 Rs principles among ecologists working with animals through a pilot online survey, and to provide strategies to contribute to responsible animal use in ecological research and education.

\section{Materials ANd Methods}

A confidential and anonymous questionnaire was designed by following several guidelines and previous studies (Boynton \& Greenhalgh, 2004; Dillman et al., 2014; Franco et al., 2018). Five researchers, who were not included in the target sample, were asked to read the questionnaire and provide feedback regarding its clarity, readability, and length. Small adjustments were made to the questionnaire following the information provided by the pilot study participants before the launch through the online platform SurveyMonkey (http://www.surveymonkey.com).

The final version of the questionnaire (Appendix 1) consisted of seven thematic sections: a) animal use in ecological research, b) ethical concerns about animal use, c) awareness of the 3Rs principles, d) animal welfare, e) animal use in education, e) training in ethics and animal welfare, and f) socio-demographic characteristics. The questionnaire started with a brief background and purpose of the survey. Respondents were informed that the completion of the questionnaire was anonymous and that responses would be used for scientific and educational purposes. The completion time was estimated to be 10 minutes. Respondents had to answer all questions within a section before being able to move on to the next section, but the option "I don't know" was available for most questions. Survey logic was used to filter questions based on previous responses to ensure question relevance.

To recruit respondents, I contacted 38 ecological and zoological societies and groups across Europe (Appendix 2, Table S1) and requested assistance with enrolling ecologists into the study through their mailing lists. As some participants notified me of doing snowball sampling, i.e. recruiting other respondents from among their acquaintances, it was not possible to determine the exact response rate. The geographical constraint was implemented due to the unified animal welfare legislation within the European Union. No incentives were provided for participation. The survey was open from the 8th of October 2018 until the 25th of January 2019. Since some of the respondents did not answer all of the questions in the questionnaire, responses to questions are reported as percentages with the actual number of respondents for each question indicated in brackets.

In order to assess any potential effect of sociodemographic factors (age, gender) on the attitudes, I used the Chi-square test for nominal variables and the Wilcoxon test for ordinal variables (Franco et al., 2018). Only fully answered questionnaires were included in the analyses $(N=96)$. Significance for all tests was set at $\mathrm{p}<0.05$. All statistical analyses were conducted in R 3.3.3 (R Core Team, 2017).

\section{Results}

\section{Socio-demographic characteristics}

In total, 107 respondents from 23 countries fully or partially completed the questionnaire. Forty-seven percent of the respondents were females, 52\% were males, and one percent chose not to reveal their gender. Ninety-six respondents chose to provide an-

\section{A) AGE OF THE RESPONDENTS}

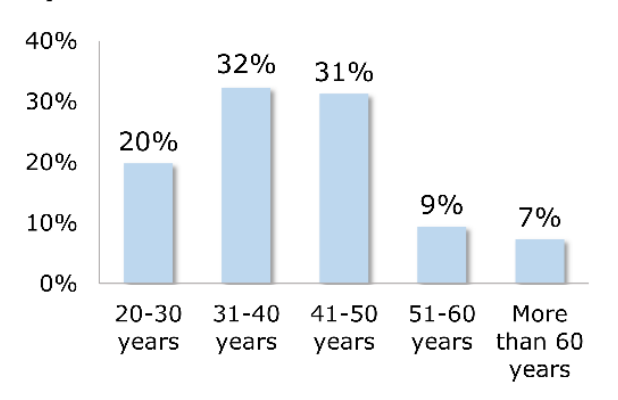

\section{B) OCCUPATION OF THE RESPONDENTS}

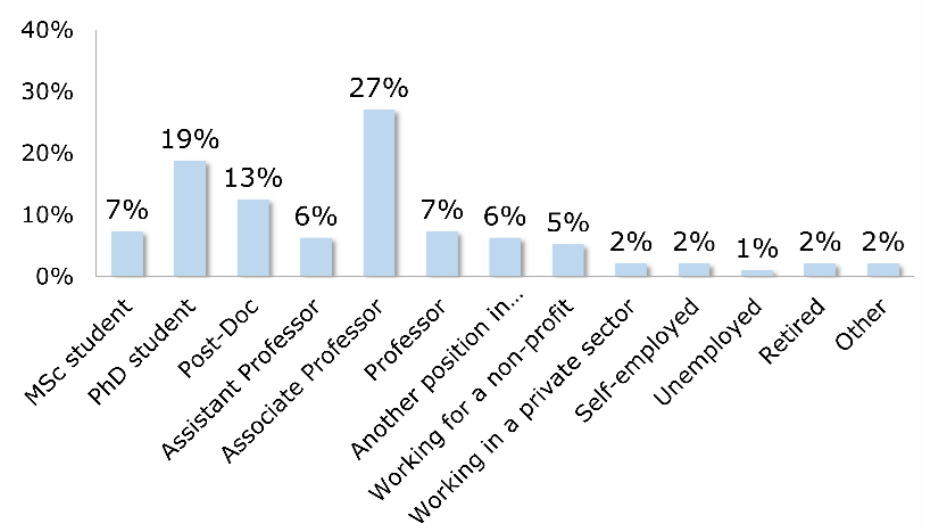

Figure 2: Age (A) and occupation (B) of the respondents $(\mathrm{N}=96)$. 
swers about their socio-demographic characteristics. The majority of respondents were either from France (22\%), Germany (20\%), or the Czech Republic (9\%). Although this survey targeted researchers residing in Europe, six non-EU countries were also represented (Appendix, Table S2). The majority of respondents belonged to the age groups $31-40$ years old $(32 \%)$ and 41-50 years old (31\%; Fig. 2A). PhD students, Post-Docs, and Associate Professors constituted half of the respondents (Fig. 2B).

\section{Animal use in ecological research and awareness of the 3 Rs principles}

Majority of the respondents (64\%) used in their latest research more than 100 animals (Fig. 3A; N
$=107$ ) and worked with vertebrates (Fig. 3). More than a quarter of the respondents reported that the animals in their latest research had to be killed and $18 \%$ used an invasive research technique, defined as a technique that is likely to affect animal welfare (for example, blood taking, toe-clipping, marking; Fig. $3 \mathrm{~B} ; \mathrm{N}=107)$. Only $44 \%$ of the respondents calculated the minimum sample size before they started their last study (Fig. 3C; $\mathrm{N}=107$ ).

Respondents were asked if they heard of the 3Rs principles for animal research, and if they answered "yes" they were then asked to list the principles. The majority of the respondents (55\%) admitted being completely unaware of the 3Rs principles for animal research (Fig. 3D; $\mathrm{N}=104$ ). Only $39 \%$ of the re-
A) HOW MANY INDIVIDUALS DID YOU STUDY IN YOUR LATEST RESEARCH / WORK ON ANIMALS?

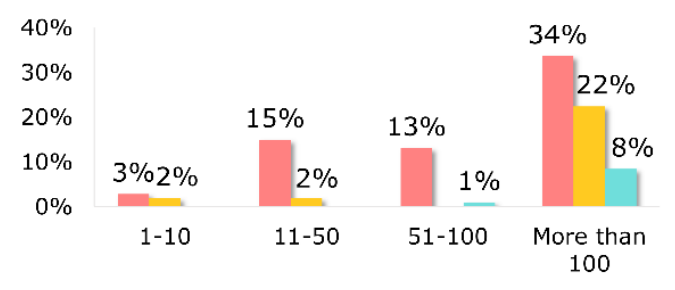

C) BEFORE YOU STARTED YOUR LAST STUDY, DID YOU OR YOUR TEAM CALCULATE THE MINIMUM SAMPLE SIZE?

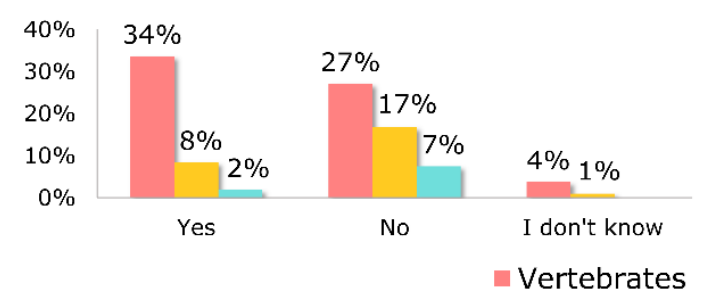

\section{B) WHAT KIND OF TECHNIQUE WAS USED?}

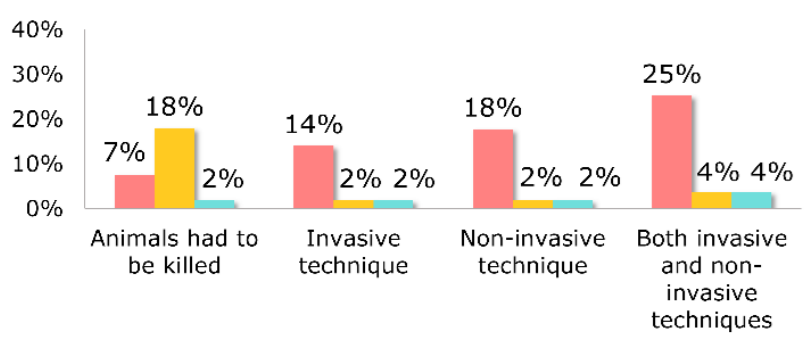

D) HAVE YOU HEARD OF THE 3RS PRINCIPLES FOR ANIMAL RESEARCH?

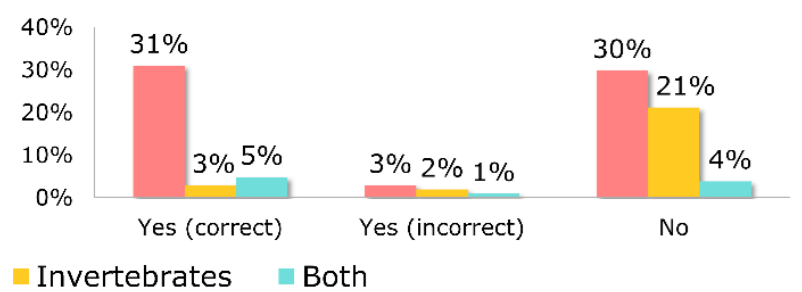

Figure 3: Number and type of animals used in the latest work of the respondents $(\mathrm{N}=107)$. $\mathrm{B})$ The technique used in the latest work of the respondents $(\mathrm{N}=107)$ : the invasive technique was defined as a technique likely affecting animal's welfare (for example, blood-taking, toe-clipping, or marking), non-invasive technique was defined as a technique without any impact on animal's welfare (for example, collection of feces or using camera traps). C) Calculation of the minimum sample in the latest work of the respondents $(\mathrm{N}=107)$. D) Awareness of the 3Rs principles for animal research among the respondents $(\mathrm{N}=104)$.
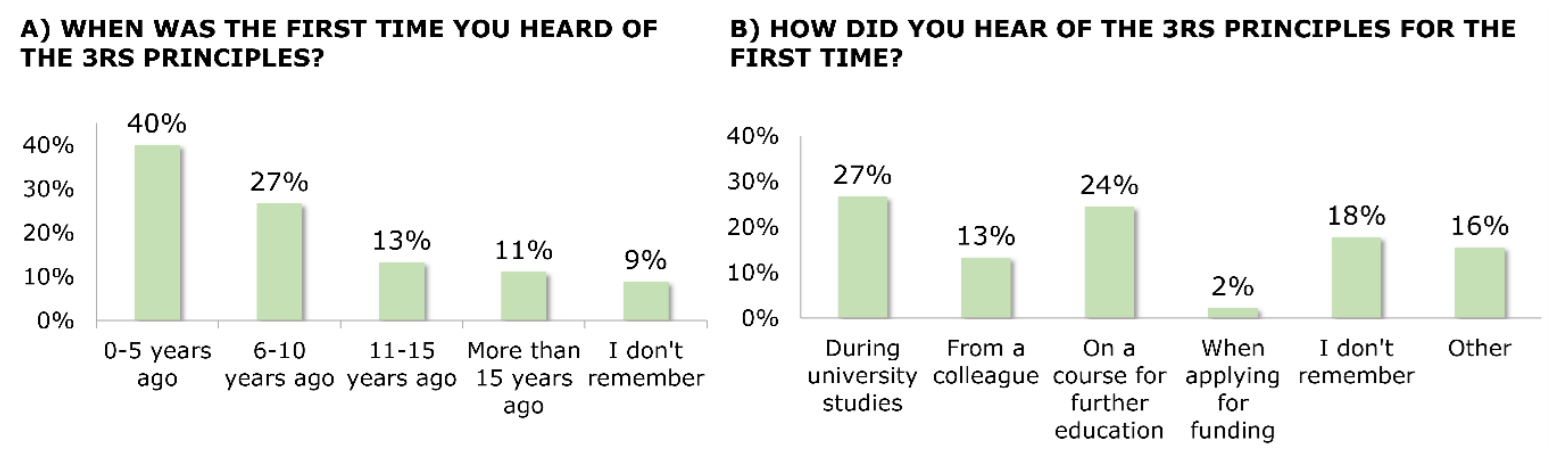

Figure 4: The first time (A) and the way (B) the respondents heard of the 3Rs principles (subsample of Fig. 3D; N = 45). 
spondents did hear of them and were able to list them correctly. The rest of the respondents $(6 \%)$ claimed that they knew the 3Rs principles, but failed to name them, or confused them with other 3Rs (e.g., the "reduce, reuse, recycle" principles for waste management). The majority of those who knew the 3Rs principles said that they first heard about them in the last 5 years ( $40 \%$; Fig. 4A; $N=45)$, and either during university studies $(27 \%)$ or in a course for further education (24\%) (Fig. 4B).

\section{Access to information about non-invasive research methods}

In terms of access to information on non-invasive research methods, $9 \%$ considered it difficult and $24 \%$ were not sure (Fig. 5A; $N=98$ ). To the question of what they perceive as barriers to implementing more non-invasive research methods into ecological research, respondents could choose multiple answers. Financial constraints, lack of awareness, and lack of established laboratory protocols were chosen most frequently (Fig. 5B; $\mathrm{N}=98$ ). Other reasons mentioned by the respondents were, e.g., that "standard methods are difficult to replace", or that "researchers are conservative-minded and do not want to change previous protocols" (Appendix, Table S3).

\section{Ethical concerns about animal use}

The majority of the respondents (66\%) experience to varying extent ethical doubts or concerns regarding animal use in their research or work (Fig. 6A; $\mathrm{N}=105$ ) and discuss the ethical aspects of their work with colleagues (Fig. 6B; $\mathrm{N}=105$ ). There were however statistically significant differences among the age groups $(p=0.006)$, with a higher proportion of the younger respondents (20-50 years old) expressing ethical concerns than older respondents $(>51$ years old). Furthermore, among respondents stating that they do experience ethical concerns (sometimes, usually, always) there was a higher proportion of women $(p=0.021)$.

\section{Training in animal welfare and ethics}

The majority of the respondents $(70 \%)$ felt that their research included sufficient consideration for animal welfare (Fig. 7A; $N=98$ ). However, the topic of animal welfare was covered in the education of only $38 \%$ of the respondents (Fig. $7 \mathrm{~B} ; \mathrm{N}=97$ ). Ethics classes were attended by only a third of the respondents (Fig. 7C, D; $N=97$ ). Still, the majority
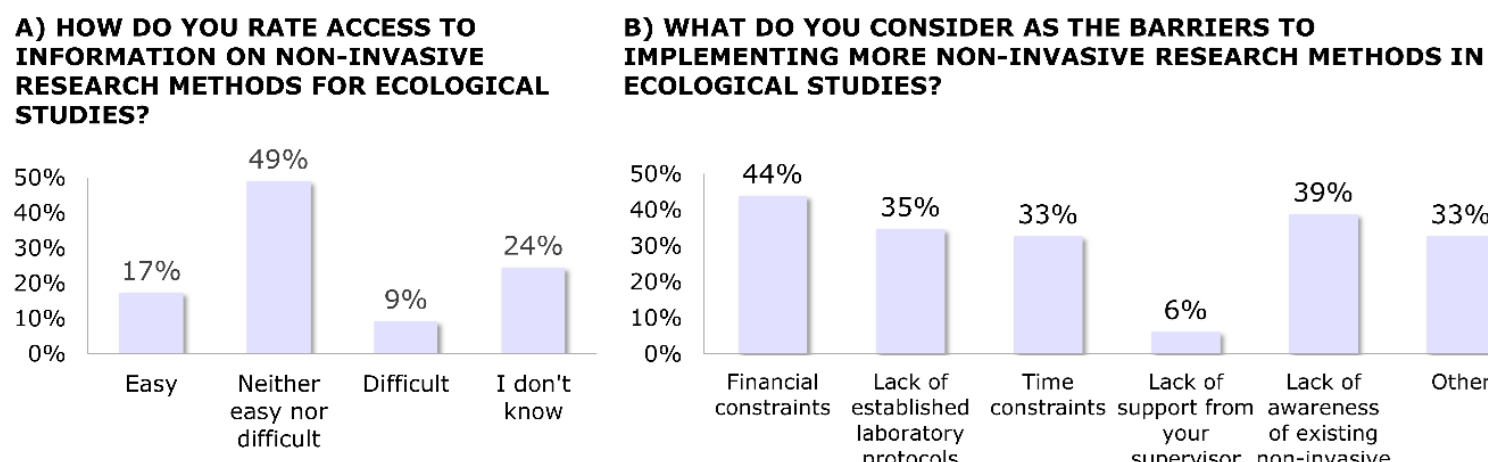
ECOLOGICAL STUDIES?

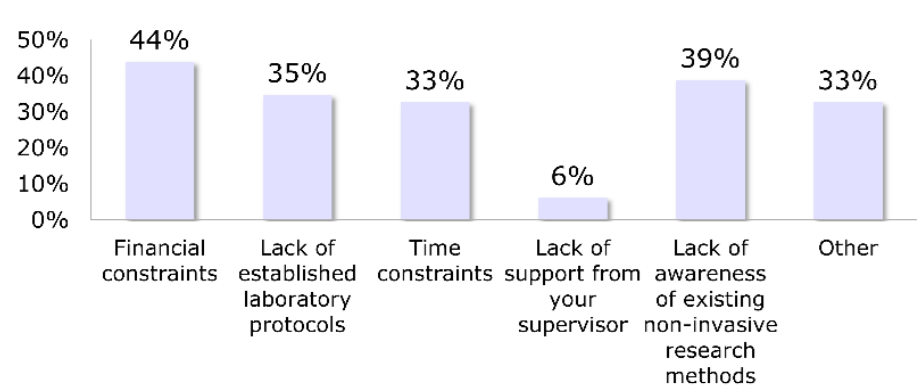

Figure 5: A) Perceived ease of access to information on non-invasive research methods among the respondents $(\mathrm{N}=98)$. B) Perceived barriers to implementing more non-invasive research methods in ecological studies among the respondents (multiple choice; $\mathrm{N}=98$ ). Detailed responses from the category “Other" are reported in Appendix, Table S3.

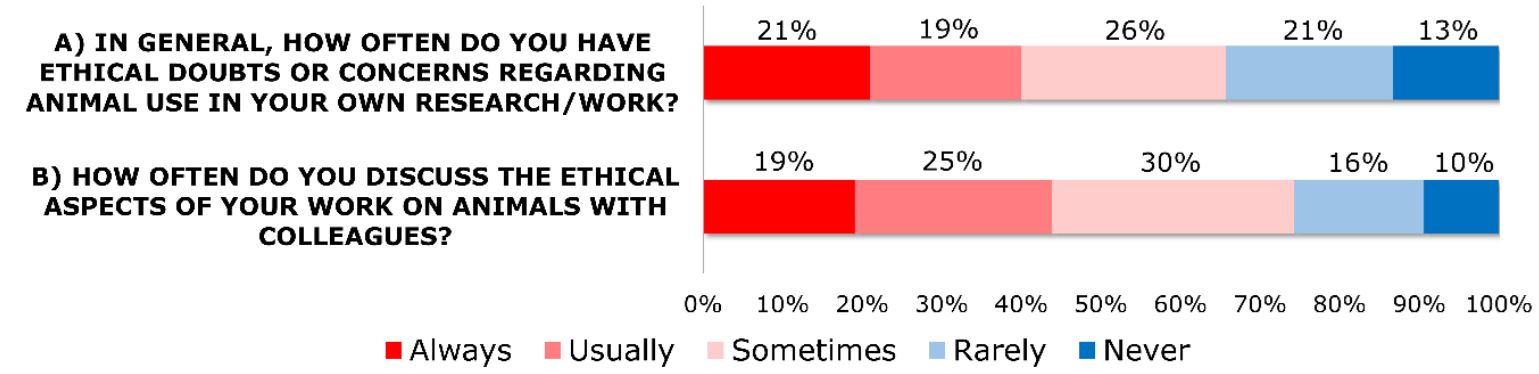

Figure 6: A) Frequency of ethical concerns regarding animal use in their work among the respondents $(\mathrm{N}=105)$. B) Frequency of discussions about the ethical aspects with colleagues $(\mathrm{N}=105)$. 


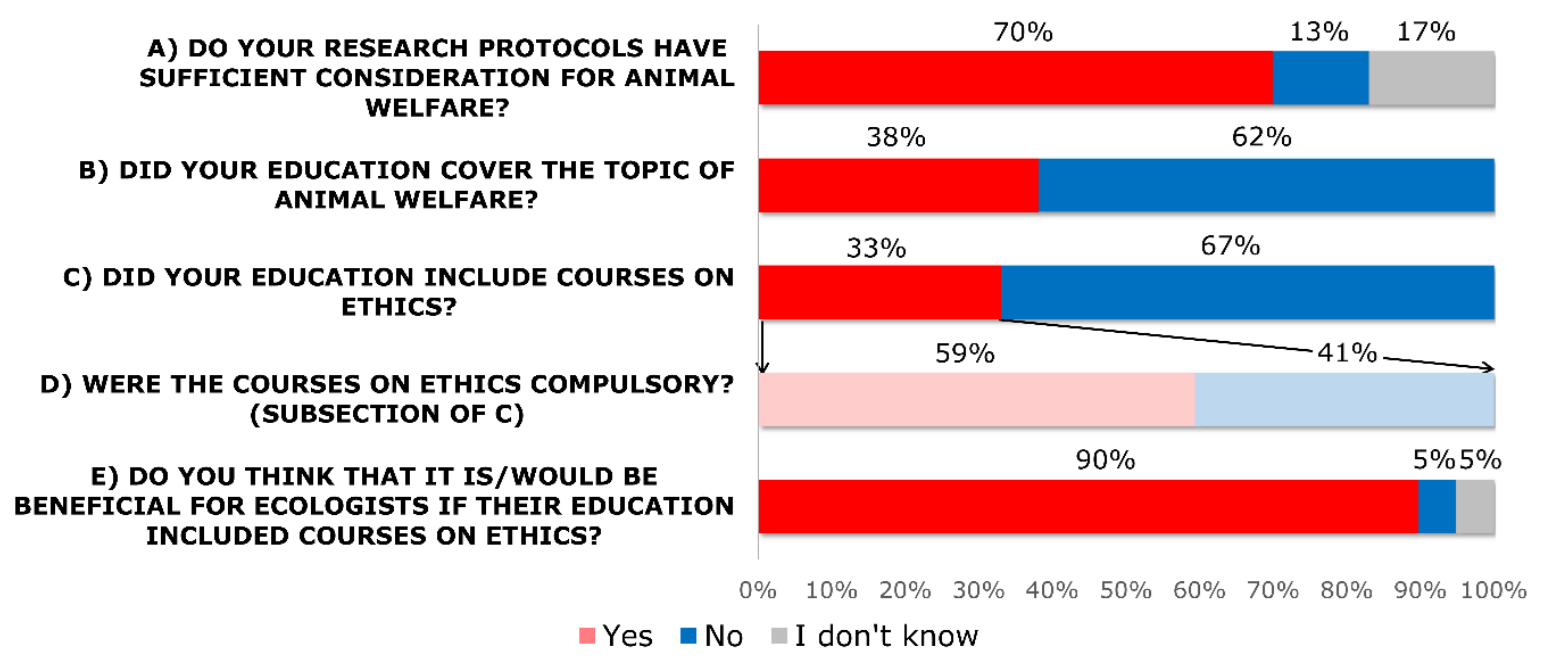

Figure 7: A) Perceived status of animal welfare consideration in research protocols of the respondents $(\mathrm{N}=98)$. B-E) Experience and opinion on animal welfare and ethics classes among the respondents $(\mathrm{N}=97)$.

\section{A) DID YOUR EDUCATION INCLUDE ANIMAL DISSECTION CLASSES?}

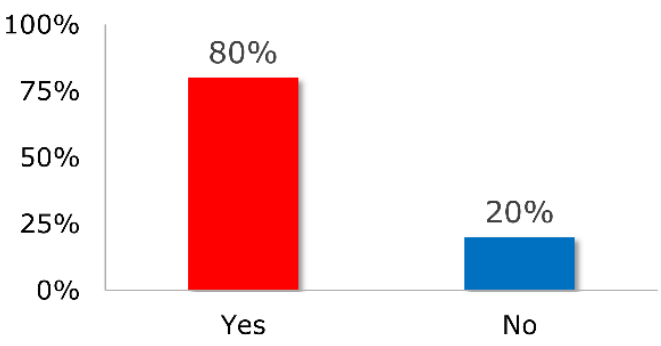

\section{B) WHAT KIND OF ANIMAL WAS DISSECTED?}

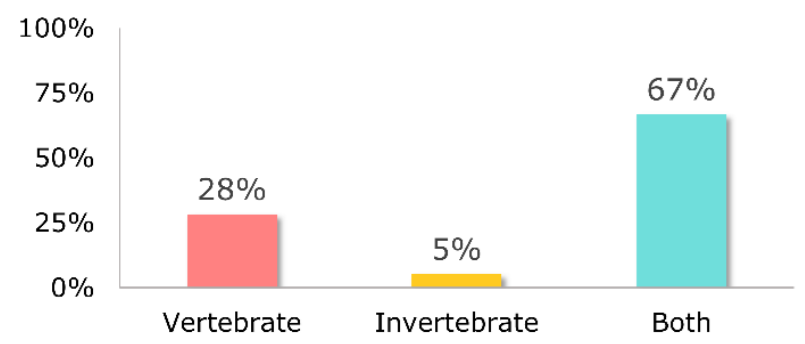

Figure 8: A) Experience with animal dissection as a part of education among the respondents $(\mathrm{N}=98)$. B) Type of animal used in dissections (subsample of Fig. 8A; $\mathrm{N}=78$ ).

of the respondents (90\%) thought that it would be beneficial for ecologists if their education included courses on ethics (Fig. 7E; $N=97$ ).

\section{Animal use in education}

For the vast majority of the respondents $(80 \%)$, animal dissection was a component of their education (Fig. 8A; $\mathrm{N}=98$ ). The respondents experienced dissection of both vertebrate and invertebrate species most frequently $(67 \%)$, followed by dissection of vertebrates (28\%; Fig. $8 \mathrm{~B} ; \mathrm{N}=78)$.

\section{Discussion}

\section{Unfamiliarity with the $3 R$ s principles}

The implementation of the 3Rs principles could help prevent research and management in which animal welfare is compromised (Zemanova, 2020). My findings however revealed that more than half of the respondents never heard of the 3 Rs principles, or were not able to list them correctly (Fig. 3D). Respondents working with invertebrates were overall less aware of the 3Rs principles than respondents working with vertebrates, but half of the respondents working with vertebrates had not heard of the 3Rs either. These responses are in accordance with other studies looking into awareness of the 3Rs principles among researchers working or intending to work with animals (Franco \& Olsson, 2014; Franco et al., 2018). Van Luijk et al. (2013) pointed out that the information about the 3 Rs principles and their implementation may be difficult to access. The issue with effective searching for the 3 Rs principles was highlighted also in the study by Leenaars et al. (2009), in which 67 scientists said that they have limited knowledge of the 3Rs databases and access to information is limited. Another important source of information about the 3 Rs principles and animal welfare are colleagues (Fig. 4B) and strengthening communication among researchers might be one of the strategies to 
distribute knowledge about the 3Rs (van Luijk et al., 2011; van Luijk et al., 2013).

Additionally, more than half of the respondents did not calculate the minimum sample size in their latest study (Fig. 3C), which is the most straightforward way to implement the principle of Reduction. While the calculation of the minimum sample size in ecological research has not been enforced (Field et al., 2019), several pioneering studies have been recently published, e.g., in seabirds (Thaxter et al., 2017) or moose (Girard et al., 2002).

\section{Prevalence of invasive research methods}

Most of the respondents worked in their latest study with vertebrates (Fig. 3) and only $22 \%$ used a non-invasive research method (Fig. 3B). This could be explained either by the non-availability of a suitable non-invasive technique or by failure to implement existing methods, as was reported in previous studies (Waugh \& Monamy, 2016; Russo et al., 2017; Zemanova, 2019). In the current survey, two of the most commonly cited barriers to implementing non-invasive research methods were time constraints and lack of awareness of existing non-invasive techniques (Fig. 5B). The lack of awareness might be mitigated with the emergence of the 3Rs guidelines and databases designed specifically for researchers working with wildlife (https://3RsWildlife.info/; Zemanova, 2021).

Specifically for invertebrates, the most common research method implemented was lethal sampling (Fig. 3B). However, we are currently still lacking research investigating the appropriateness of different methods of invertebrate euthanasia (Drinkwater et al., 2019). While invertebrates do not fall - with some exceptions - under legislation on animal protection, debates on considerations for animal welfare have recently expanded to include invertebrates as well (Adamo, 2016; Keller, 2017). With the emergence of studies pointing out invertebrates' ability to feel pain (Crook \& Walters, 2011; Elwood, 2011) and experience emotions (Bateson et al., 2011; Plowright, 2017), it might be important to exercise the precautionary principle and implement non-invasive methods even for invertebrates whenever possible.

\section{Lack of training in animal welfare and ethics}

More than two-thirds of the respondents stated that they had ethical doubts or concerns about their work at least occasionally (Fig. 6A) and discuss these concerns with their colleagues (Fig. 6B).
Consistently with other studies, my results confirmed that gender and age are some of the most significant indicators of personal attitudes and opinions about animals. Women have been shown to express more concern for animal suffering and are more likely to object to animal use (Kellert \& Berry, 1987; Herzog, 2007; Phillips et al., 2011; Magnani et al., 2017), and the use of animals in research is often less accepted among young people (Hagelin et al., 2003; Ostovic et al., 2017).

While the majority of the respondents think about the ethical implications of their work (Fig. 7A), they rarely receive training in animal welfare and ethics (Fig. 7B, C). This result is consistent with my previous work (Zemanova, 2017) in which I determined that majority of undergraduate biology programs at European universities do not provide stand-alone courses in animal ethics. Courses in ethics could help ecologists navigate the terrain of moral problems encountered during their work (Appendix, Table S3; Zemanova, 2017), and animal welfare classes can increase the confidence of the students when handling animals (Hazel et al., 2011; Johnstone et al., 2019).

\section{Animal dissection is an intrinsic part of education in ecology}

The responses from the survey also suggest that dissections might be a very much ingrained part of education in ecology (Fig. 8). Animal dissection for educational purposes is, however, a highly controversial topic, with several studies contesting this practice on environmental, economic, and ethical grounds (Hug, 2008; Oakley, 2013). Several studies have shown that the educational merit of dissection is often very low in comparison with humane teaching alternatives (Lalley et al., 2010; Lombardi et al., 2014; Moro et al., 2017; Zemanova \& Knight, 2021). Following the 3 Rs principles, the shift towards using non-harmful animal use and animal-free alternatives that we witness in medical (Pawlowski et al., 2018; Gala \& Crandall, 2019) and veterinary education (Pereira et al., 2017; Grevemeyer \& Knight, 2018) should be implemented in all life sciences - including ecology.

\section{Limitations of the survey results}

It is important to note that there are two major limitations of this survey. Firstly, the questions may not have captured the full range of animal use in ecological research and education. Secondly, even though the rather small sample size is comparable 
or even larger than in some other studies on the 3Rs implementation and attitudes towards animal welfare (e.g. Leenaars et al., 2009; van Luijk et al., 2013; Dignon, 2016), the results of the survey cannot be interpreted as generally representative of the attitudes and experience of all ecologists working with animals. Therefore, caution should be exercised when interpreting the responses. Nevertheless, the respondents represented a wide range of nationalities, ages, genders, and positions, and it should be therefore possible to draw some general tendencies in the attitudes and experiences.

\section{Conclusions}

The question of how we can ensure responsible research using animals remains a controversial and sensitive issue that needs to be addressed also within the ecological research community. The results of this pilot study pointed out that careful consideration of how the 3Rs principles, animal welfare, and ethics in ecological research are taught, communicated, and enforced is necessary and overdue. In summary, it is important to 1) keep raising awareness of the 3Rs principles for animal research among ecologists, 2) support the implementation of non-invasive research methods through grants and institutional assistance in order to ensure no unnecessary harm to research animals, 3) promote courses in statistics for ecological study design, 4) establish compulsory education in animal welfare and animal ethics, 5) move away from dissections towards non-harmful animal use or animal-free alternatives, and 6) encourage peer discussions about responsible animal use. The findings reported here could serve as a baseline for assessing the success of such measures.

\section{ACKNOWLedgments}

This work was supported by the Animalfree Research foundation. I thank all the ecologists that dedicated their time to complete the survey, as well as the organizations that helped publicize it. I would also like to express my deepest gratitude to Markus Wild for his support. The icons used in Fig. 1 are from flaticon.com (improved wildlife welfare, legislative compliance, and public support by Freepik; ethical framework and robust science by Eucalyp; lower costs by Nhor Phai; sparked innovation by DinosoftLabs).

\section{CONFLICTS OF INTEREST}

None declared.

\section{Author Contributions}

MAZ declares being the sole author of this work.

\section{Data Availability Statement}

All results and wording of the questionnaire are reported in the main text and appendices. The raw data that support the findings of this study are available on request from the corresponding author.

\section{REFERENCES}

Adamo, S.A. (2016) Do insects feel pain? A question at the intersection of animal behaviour, philosophy and robotics. Anim. Behav., 118, 75-79. doi: 10.1016/j.anbehav.2016.05.005.

Alldredge, M.W., Blecha, T. \& Lewis, J.H. (2019) Less invasive monitoring of cougars in colorado's front range. Wildl. Soc. Bull., 43, 222-230. doi: 10.1002/wsb.971.

Bateson, M., Desire, S., Gartside, S.E. \& Wright, G.A. (2011) Agitated honeybees exhibit pessimistic cognitive biases. Curr. Biol., 21, 1070-1073. doi: 10.1016/j.cub.2011.05.017.

Beausoleil, N.J. (2014) Balancing the need for conservation and the welfare of individual animals. Dilemmas in Animal Welfare (ed. by M.C. Appleby, D.M. Weary and P. Sandoe), pp. 124-147. C.A.B. International, Wallingford, UK.

Blattner, C. (2014) 3R for farmed animals: a legal argument for consistency. Global Journal of Animal Law, 1, 1-26. doi: http://ojs.abo.fi/ojs/index.php/ gjal/article/view/1303.

Boynton, P.M. \& Greenhalgh, T. (2004) Handson guide to questionnaire research: selecting, designing, and developing your questionnaire. Br. Med. J., 328, 1312-1315. doi: 10.1136/bmj.328.7451.1312.

Bruskotter, J.T., Vucetich, J.A., Dietsch, A., Slagle, K.M., Brooks, J.S. \& Nelson, M.P. (2019) Conservationists' moral obligations toward wildlife: values and identity promote conservation conflict. Biol. Conserv., 240, 108296. doi: 10.1016/j.biocon.2019.108296.

Cooke, S.J., Birnie-Gauvin, K., Lennox, R.J., Taylor, J.J., Rytwinski, T., Rummer, J.L., Franklin, C.E., Bennett, J.R. \& Haddaway, N.R. (2017) How experimental biology and ecology can support evidence-based decision-making in conservation: avoiding pitfalls and enabling application. Conservation Physiology, 5, cox043. doi: 10.1093/conphys/ $\operatorname{cox} 043$.

Costello, M.J., Beard, K.H., Corlett, R.T., Cumming, G.S., Devictor, V., Loyola, R., Maas, B., Mill- 
er-Rushing, A.J., Pakeman, R. \& Primack, R.B. (2016) Field work ethics in biological research. Biol. Conserv., 203, 268-271. doi: 10.1016/j.biocon.2016.10.008.

Crook, R.J. \& Walters, E.T. (2011) Nociceptive behavior and physiology of molluscs: animal welfare implications. ILAR journal, 52, 185-195. doi: 10.1093/ilar.52.2.185.

de Jong, A. (2019) Less is better. Avoiding redundant measurements in studies on wild birds in accordance to the principles of the 3Rs. Frontiers in Veterinary Science, 6, 195. doi: 10.3389/fvets.2019.00195.

Dignon, A. (2016) 'I think it will eventually be done away with': attitudes among healthcare professionals towards the current system of animal experimentation. J. Health Psychol., 21, 1630-1643. doi: $10.1177 / 1359105314559862$.

Dillman, D.A., Smyth, J.D. \& Christian, L.M. (2014) Internet, Phone, Mail, and Mixed-Mode Surveys: The Tailored Design Method, 4th edn. John Wiley \& Sons Inc., Hoboken, NJ.

Drinkwater, E., Robinson, E.J. \& Hart, A.G. (2019) Keeping invertebrate research ethical in a landscape of shifting public opinion. Methods Ecol. Evol., 10, 1265-1273. doi: 10.1111/2041210X.13208.

Elwood, R.W. (2011) Pain and suffering in invertebrates? ILAR journal, 52, 175-184. doi: 10.1093/ ilar.52.2.175.

Field, K.A., Paquet, P.C., Artelle, K., Proulx, G., Brook, R.K. \& Darimont, C.T. (2019) Publication reform to safeguard wildlife from researcher harm. PLoS Biol., 17, e3000193. doi: 10.1371/journal. pbio.3000193.

Ford, B., Govindarajulu, P., Larsen, K. \& Russello, M. (2017) Evaluating the efficacy of non-invasive genetic sampling of the Northern Pacific rattlesnake with implications for other venomous squamates. Conservation Genetics Resources, 9, 13-15. doi: 10.1007/s12686-016-0606-z.

Franco, N.H. \& Olsson, I.A.S. (2014) Scientists and the 3Rs: attitudes to animal use in biomedical research and the effect of mandatory training in laboratory animal science. Lab. Anim., 48, 50-60. doi: 10.1177/0023677213498717.

Franco, N.H., Sandoe, P. \& Olsson, I.A.S. (2018) Researchers' attitudes to the 3Rs - an upturned hierarchy? PLoS One, 13, e0200895. doi: 10.1371/journal.pone.0200895.

Fraser, D. \& MacRae, A.M. (2011) Four types of activities that affect animals: implica- tions for animal welfare science and animal ethics philosophy. Anim. Welfare, 20, 581-590. doi: https://www.ingentaconnect.com/content/ufaw/ aw/2011/00000020/00000004/art00012.

Gala, S.G. \& Crandall, M.L. (2019) Global collaboration to modernize advanced trauma life support training. J. Surg. Educ., 76, 487-496. doi: 10.1016/j. jsurg.2018.08.011.

Girard, I., Ouellet, J.P., Courtois, R., Dussault, C. \& Breton, L. (2002) Effects of sampling effort based on GPS telemetry on home-range size estimations. J. Wildl. Manage., 66, 1290-1300. doi: $10.2307 / 3802962$.

Grevemeyer, B. \& Knight, A. (2018) The development of a clinical skills laboratory at Ross University School of Veterinary Medicine. ATLA, 46, 177183. doi: 10.1177/026119291804600305.

Hagelin, J., Carlsson, H.E. \& Hau, J. (2003) An overview of surveys on how people view animal experimentation: some factors that may influence the outcome. Public Understanding of Science, 12, 6781. doi: 10.1177/0963662503012001247.

Harcourt, R.G., Turner, E., Hall, A., Waas, J.R. \& Hindell, M. (2010) Effects of capture stress on free-ranging, reproductively active male Weddell seals. Journal of Comparative Physiology, 196, 147154. doi: 10.1007/s00359-009-0501-0.

Hazel, S.J., Signal, T.D. \& Taylor, N. (2011) Can teaching veterinary and animal-science students about animal welfare affect their attitude toward animals and human-related empathy? J. Vet. Med. Educ., 38, 74-83. doi: 10.3138/jvme.38.1.74.

Herzog, H.A. (2007) Gender differences in human-animal interactions: a review. Anthrozoos, 20, 7-21. doi: 10.2752/089279307780216687.

Hodgson, J.C., Mott, R., Baylis, S.M., Pham, T.T., Wotherspoon, S., Kilpatrick, A.D., Segaran, R.R., Reid, I., Terauds, A. \& Koh, L.P. (2018) Drones count wildlife more accurately and precisely than humans. Methods Ecol. Evol., 9, 1160-1167. doi: 10.1111/2041-210x.12974.

Hone, J., Drake, V.A. \& Krebs, C.J. (2018) Evaluating wildlife management by using principles of applied ecology: case studies and implications. Wildl. Res., 45, 436-445. doi: 10.1071/wr18006.

Hug, B. (2008) Re-examining the practice of dissection: what does it teach? Journal of Curriculum Studies, 40, 91-105. doi: 10.1080/00220270701484746.

Hurst, J.L. \& West, R.S. (2010) Taming anxiety in laboratory mice. Nat. Methods, 7, 825-826. doi: 10.1038/nmeth. 1500 . 
IPBES (2019) Global Assessment Report on Biodiversity and Ecosystem Services. In: eds. S. Díaz, J. Settele, E.S. Brondizio, H.T. Ngo, M. Guèze, J. Agard, A. Arneth, P. Balvanera, K.A. Brauman, S.H.M. Butchart, K.M.A. Chan, L.A. Garibaldi, K. Ichii, J. Liu, S.M. Subramanian, G.F. Midgley, P. Miloslavich, Z. Molnár, D. Obura, A. Pfaff, S. Polasky, A. Purvis, J. Razzaque, B. Reyers, R.R. Chowdhury, Y.J. Shin, I.J. Visseren-Hamakers, K.J. Willis and C.N. Zayas), Bonn, Germany.

Jewell, Z. (2013) Effect of monitoring technique on quality of conservation science. Conserv. Biol., 27, 501-508. doi: 10.1111/cobi.12066.

Johnstone, E.C., Frye, M.A., Lord, L.K., Baysinger, A.K. \& Edwards-Callaway, L.N. (2019) Knowledge and opinions of third year veterinary students relevant to animal welfare before and after implementation of a core welfare course. Frontiers in Veterinary Science, 6, 103. doi: 10.3389/ fvets.2019.00103.

Keller, M. (2017) Feeding live invertebrate prey in zoos and aquaria: are there welfare concerns? Zoo Biol., 36, 316-322. doi: 10.1002/zoo.21378.

Kellert, S.R. \& Berry, J.K. (1987) Attitudes, knowledge, and behaviors toward wildlife as affected by gender. Wildl. Soc. Bull., 15, 363-371. doi: https://www.jstor.org/stable/3782542.

Kersey, D.C. \& Dehnhard, M. (2014) The use of noninvasive and minimally invasive methods in endocrinology for threatened mammalian species conservation. Gen. Comp. Endocrinol., 203, 296-306. doi: 10.1016/j.ygcen.2014.04.022.

Lalley, J.P., Piotrowski, P.S., Battaglia, B., Brophy, K. \& Chugh, K. (2010) A comparison of V-Frog $($ to physical frog dissection. International Journal of Environmental and Science Education, 5, 189-200. doi: http://www.ijese.net/makale/1416. html.

Leenaars, M., Savenije, B., Nagtegaal, A., van der Vaart, L. \& Ritskes-Hoitinga, M. (2009) Assessing the search for and implementation of the Three Rs: a survey among scientists. ATLA, 37, 297-303. doi: 10.1177/026119290903700312.

Lefort, M.C., Cruickshank, R.H., Descovich, K., Adams, N.J., Barun, A., Emami-Khoyi, A., Ridden, J., Smith, V.R., Sprague, R., Waterhouse, B. \& Boyer, S. (2019) Blood, sweat and tears: a review of non-invasive DNA sampling. bioRxiv, 385120. doi: 10.1101/385120.

Lombardi, S.A., Hicks, R.E., Thompson, K.V. \& Marbach-Ad, G. (2014) Are all hands-on activities equally effective? Effect of using plastic models, organ dissections, and virtual dissections on student learning and perceptions. Adv. Physiol. Educ., 38, 80-86. doi:

MacRae, A.M., Makowska, I.J. \& Fraser, D. (2018) Initial evaluation of facial expressions and behaviours of harbour seal pups (Phoca vitulina) in response to tagging and microchipping. Appl. Anim. Behav. Sci., 205, 167-174. doi: 10.1016/j.applanim.2018.05.001.

Magnani, D., Ferri, N., Dalmau, A. \& Messori, S. (2017) Knowledge and opinions of veterinary students in Italy toward animal welfare science and law. Vet. Rec., 180, 225-233. doi: 10.1136/vr.103938.

McMahon, C.R., Bradshaw, C.J.A. \& Hays, G.C. (2007) Applying the heat to research techniques for species conservation. Conserv. Biol., 21, 271-273. doi: 10.1111/j.1523-1739.2006.00566.x.

Molina, S., Fuller, A.K., Morin, D.J. \& Royle, J.A. (2017) Use of spatial capture-recapture to estimate density of Andean bears in northern Ecuador. Ursus, 28, 117-126. doi: 10.2192/URSUD-16-00030.1.

Montané, J., Marco, I., Manteca, X., López, J. \& Lavín, S. (2002) Delayed acute capture myopathy in three roe deer. Journal of Veterinary Medicine Series A, 49, 93-98. doi: 10.1046/j.1439-0442.2002. jv409.x.

Moro, C., Štromberga, Z., Raikos, A. \& Stirling, A. (2017) The effectiveness of virtual and augmented reality in health sciences and medical anatomy. Anatomical Sciences Education, 10, 549-559. doi: 10.1002/ase.1696.

Oakley, J. (2013) “I didn't feel right about animal dissection". Dissection objectors share their science class experiences. Society \& Animals, 21, 360-378. doi: 10.1163/15685306-12341267.

Ostovic, M., Mikus, T., Pavicic, Z., Matkovic, K. \& Mesic, Z. (2017) Influence of socio-demographic and experiential factors on the attitudes of Croatian veterinary students towards farm animal welfare. Vet. Med. (Praha), 62, 417-428. doi: 10.17221/172/2016-vetmed.

Pawlowski, J.B., Feinstein, D.M. \& Gala, S.G. (2018) Developments in the transition from animal use to simulation-based biomedical education. Simulation in Healthcare, 13, 420-426. doi: 10.1097/ sih.0000000000000310.

Pereira, G.D., Dieguez, J., Demirbas, Y.S. \& Menache, A. (2017) Alternatives to animal use in veterinary education: a growing debate. Ankara Univ. Vet. Fak., 64, 235-239. doi: 10.1501/Vetfak_0000002804. 
Phillips, C., Izmirli, S., Aldavood, J., Alonso, M., Choe, B., Hanlon, A., Handziska, A., Illmann, G., Keeling, L., Kennedy, M., Lee, G., Lund, V., Mejdell, C., Pelagic, V. \& Rehn, T. (2011) An international comparison of female and male students' attitudes to the use of animals. Animals, 1, 7-26. doi: 10.3390/ani1010007.

Plowright, C.M.S. (2017) Bumblebees at work in an emotion-like state. Learn. Behav., 45, 207-208. doi: 10.3758/s13420-017-0265-2.

Pollo, S., Vitale, A., Gayle, V. \& Zucco, F. (2004) The '3Rs' model and the concept of alternatives in animal research: a questionnaire survey. Lab Animal, 33, 47-53. doi: 10.1038/laban0704-47.

Ponjoan, A., Bota, G., De La Morena, E.L.G., Morales, M.B., Wolff, A., Marco, I. \& Manosa, S. (2008) Adverse effects of capture and handling little bustard. The Journal of Wildlife Management, 72, 315-319. doi: 10.2193/2006-443.

Poole, T. (1997) Happy animals make good science. Lab. Anim., 31, 116-124. doi: 10.1258/002367797780600198.

Powell, R.A. \& Proulx, G. (2003) Trapping and marking terrestrial mammals for research: integrating ethics, performance criteria, techniques, and common sense. ILAR journal, 44, 259-276. doi: 10.1093/ilar.44.4.259.

Prescott, M.J. \& Lidster, K. (2017) Improving quality of science through better animal welfare: the NC3Rs strategy. Lab Animal, 46, 152. doi: 10.1038/ laban.1217.

R Core Team (2017) R: a language and environment for statistical computing. doi: http:/www.R-project.org.

Russell, W.M.S. (1995) The development of the 3Rs concept. ATLA, 23, 298-304. doi:

Russell, W.M.S. \& Burch, R.L. (1959) The Principles of Humane Experimental Technique. Methuen, London, UK.

Russo, D., Ancillotto, L., Hughes, A.C., Galimberti, A. \& Mori, E. (2017) Collection of voucher specimens for bat research: conservation, ethical implications, reduction, and alternatives. Mamm. Rev., 47, 237-246. doi: 10.1111/mam.12095.

Smith, E.S.J. \& Lewin, G.R. (2009) Nociceptors: a phylogenetic view. Journal of Comparative Physiology A, 195, 1089-1106. doi: 10.1007/s00359-0090482-z.

Thaxter, C.B., Clark, N.A., Ross-Smith, V.H., Conway, G.J., Bouten, W. \& Burton, N.H.K. (2017) Sample size required to characterize area use of tracked seabirds. J. Wildl. Manage., 81, 1098-1109. doi: 10.1002/jwmg.21283.

van Luijk, J., Cuijpers, Y., van der Vaart, L., Leenaars, M. \& Ritskes-Hoitinga, M. (2011) Assessing the search for information on Three Rs methods, and their subsequent implementation: a national survey among scientists in the Netherlands. ATLA, 39, 429447. doi: 10.1177/026119291103900505.

van Luijk, J., Cuijpers, Y., van der Vaart, L., de Roo, T.C., Leenaars, M. \& Ritskes-Hoitinga, M. (2013) Assessing the application of the 3Rs: a survey among animal welfare officers in the Netherlands. Lab. Anim., 47, 210-219. doi: 10.1177/0023677213483724.

Waugh, C.A. \& Monamy, V. (2016) Opposing lethal wildlife research when nonlethal methods exist: scientific whaling as a case study. Journal of Fish and Wildlife Management, 7, 231-236. doi: 10.3996/072015-jfwm-061.

Wurbel, H. (2017) More than 3Rs: the importance of scientific validity for harm-benefit analysis of animal research. Lab Animal, 46, 164-166. doi: 10.1038/laban.1220.

Zemanova, M.A. (2017) More training in animal ethics needed for European biologists. Bioscience, 67, 301-305. doi: 10.1093/biosci/biw177.

Zemanova, M.A. (2019) Poor implementation of non-invasive sampling in wildlife genetics studies. Rethinking Ecology, 4, 119-132. doi: 10.3897/ rethinkingecology.4.32751.

Zemanova, M.A. (2020) Towards more compassionate wildlife research through the 3 Rs principles: moving from invasive to non-invasive methods. Wildl. Biol., 2020, wlb.00623. doi: 10.2981/ wlb.00607.

Zemanova, M.A. (2021) New online resource on the 3Rs principles of animal research for wildlife biologists, ecologists, and conservation managers. Conservation, 1, 106-112. doi: 10.3390/conservation 1020009.

Zemanova, M.A. \& Knight, A. (2021) The educational efficacy of humane teaching methods: a systematic review of the evidence. Animals, 11, 114. doi: 10.3390/ani11010114.

Zemanova, M.A., Knop, E. \& Heckel, G. (2017a) Introgressive replacement of natives by invading Arion pest slugs. Sci. Rep., 7, 14908. doi: 10.1038/ s41598-017-14619-y.

Zemanova, M.A., Perotto-Baldivieso, H.L., Dickins, E.L., Gill, A.B., Leonard, J.P. \& Wester, D.B. (2017b) Impact of deforestation on habitat con- 
nectivity thresholds for large carnivores in tropical forests. Ecological Processes, 6, 21. doi: 10.1186/ s13717-017-0089-1.

Zhang, B., Korolj, A., Lai, B.F.L. \& Radisic, M. (2018) Advances in organ-on-a-chip engineering. Nature Reviews Materials, 3, 257-278. doi: 10.1038/ s41578-018-0034-7. 


\section{APPENDIX 1}

Data A1: Questionnaire

爻光 University of Bosel
on

\section{Animal use in ecological research and education}

\section{Welcome}

Welcome to the survey on animal use in ecological research and education!

This survey is being conducted by the University of Basel in Switzerland in order to understand how ecologists conduct and think about their studies on animals.

Please take a moment to complete this short questionnaire. Your responses will help us to assess the current situation and propose suggestions for improvement.

The questionnaire is anonymous and should take a maximum of 10 minutes to complete.

If you have any questions about the survey please feel free to contact Dr. Miriam Zemanova by email at miriam.zemanova@unibas.ch.

Thank you!

\section{然兼 University Animal use in ecological research and education}

Animal use in ecological research

How many individuals did you study in your latest research/work on animals?
$1-10$
$11-50$
$51-100$
More than 100

What kind of animal did you study?
Vertebrate
Invertebrate
Both
Other (please specify) 
What type of technique was used?

Animals had to be killed

Invasive technique - likely affecting animal's welfare (for example: blood taking, toe-clipping, marking)

Non-invasive technique - without any impact on animal's welfare (for example: collection of feces, camera traps)

Both invasive and non-invasive techniques were used

I'm not sure

Other (please specify)

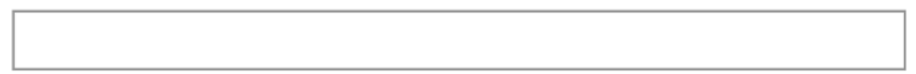

Before you started your last study, did you or your team calculate the minimum sample size?
Yes
No
I don't know

\section{整然 University Animal use in ecological research and education}

\section{Ethical concerns}

In general, how often do you have ethical doubts or concerns regarding animal use in your own research/work?
Always
Usually
Sometimes
Rarely
Never

How often do you discuss the ethical aspects of your work on animals with colleagues?
Always
Usually
Sometimes
Rarely
Never

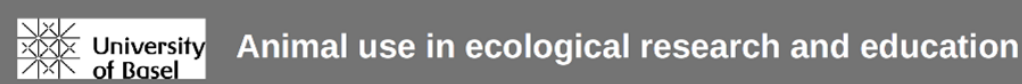




\section{Rs principles}

Have you heard of the 3Rs principles for animal research?

$\bigcirc$ Yes

No

\section{然 University Animal use in ecological research and education}

3Rs principles - continued

Could you please list the 3Rs principles?

When was the first time you heard of the $3 \mathrm{R}$ s principles?
0-5 years ago
6-10 years ago
$11-15$ years ago
More than 15 years ago
I don't remember

How did you hear of the 3Rs principles for the first time?
During university studies
From a colleague
On a course for further education
When applying for funding
I don't remember
Other (please specify)

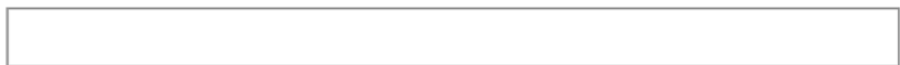

\section{University Animal use in ecological research and education}

Considering animal welfare in ecology 
Do your research protocols have sufficient consideration for animal welfare?

Yes

No

I don't know

How do you rate access to information on non-invasive research methods for ecological studies?

Easy

Neither easy nor difficult

Difficult

I don't know

What do you consider as the barriers to implementing more non-invasive research methods in ecological studies? (select all that apply)

Financial constraints

Lack of established laboratory protocols

Time constraints

$\square$ Lack of support from your supervisor

$\square$ Lack of awareness of existing non-invasive research methods

$\square$ Other (please specify)

\section{然 University Animal use in ecological research and education}

Animal use in education

Did your education include animal dissection classes?

Yes

No

\section{桨桨 University Animal use in ecological research and education}

\section{Dissection classes}


What kind of animal was dissected?
Vertebrate
Invertebrate
Both

\section{University Animal use in ecological research and education
of Bosel}

\section{Education}

Did your education cover the topic of animal welfare?

Yes

No

Did your education include courses on ethics?

Yes

No

\section{茨萑 University Animal use in ecological research and education}

\section{Education - philosophy}

Were the courses on ethics compulsory?

Yes

No

\section{瓷 University Animal use in ecological research and education}

\section{Education - ethics}

Do you think that it is/would be beneficial for ecologists if their education included courses on ethics?
Yes
No
I don't know 


\section{桬 University Animal use in ecological research and education}

Socio-demographic characteristics

In this last section, we would like to know a little bit about you - your gender, age, country of residence and occupation.

These characteristics will help us put your responses into context.

What is your gender?

Female
Male
Other

What is your age?

Less than 20 years

20-30 years

31-40 years

41-50 years

51-60 years

More than 60 years

What is your country of residence?

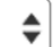


Which of the following best describes your current occupation?

MSc student
PhD student
Post-Doc
Assistant Professor / Junior Researcher
Associate Professor / Senior Researcher
Professor
Working in another position in academia
Working for a non-profit
Working in a private sector
Self-employed
Unemployed
Retired




\section{APPENDiX 2}

\section{SUPPLEMENTARY TABLES}

Table S1: Ecological societies and wildlife research groups that were contacted in order to recruit questionnaire participants.

GEOGRAPHICAL COVERAGE

ALBANIA
AUSTRIA
AUSTRIA
BELGIUM
BOSNIA AND HERZEGOVINA
CROATIA
CZECH REPUBLIC
DENMARK
FINLAND
FRANCE
FRANCE
GERMANY
GERMANY
GERMANY
GERMANY, AUSTRIA,
SWITZERLAND
GREECE
HUNGARY
ICELAND
IRELAND
ITALY
MACEDONIA
MOLDOVA
NETHERLANDS
NORWAY
POLAND
PORTUGAL
ROMANIA
SERBIA AND MONTENEGRO
SPAIN
SPAIN
SPAIN
SWEDEN
SWITZERLAND
UK
EU
EU
WORLDWIDE
WORLDWIDE
WORAGE

\section{SOCIETY / GROUP}

Institute for Nature Conservation in Albania

Austrian Entomological Society

Zoological-Botanical Society Austria

Belgian Biodiversity Platform

Society for Biological Research and Protection of Nature

Croatian Ecological Society

Czech Society for Ecology

Danish Society Oikos

Finnish Association for Nature Protection

French Society for Ecology

French Society for the Study of Animal Behavior

German Society for Mammalian Biology

German Zoological Society

German Society of General and Applied Entomology

Ecological Society of Germany, Austria and Switzerland (Face-

book group)

HELECOS Hellenic Ecological Society

Hungarian Ecological Society

Ecological Society of Iceland

Irish Ecological Association

Italian Ecological Society

Macedonian Ecological Society

Biotica Ecological Society Moldova

Dutch-Flemish Association for Ecology

Norwegian Organic Society

Naturalist's Club

Portuguese Ecological Society

Romanian Ecological Society

Ecological Society Endemit Serbia and Montenegro

Spanish Association of Land Ecology (Facebook group)

Spanish Society for the Conservation and Study of Mammals

(FACEBOOK group)

Spanish Ecological Society

Swedish Oikos Society (Facebook group)

Swiss Society of Wildlife Biology

British Ecological Society (Facebook group)

European Ecological Federation

Society for Conservation Biology Europe (Facebook group)

Ecology and Evolutionary Biology (Facebook group)

Wildlife Biologists (Facebook group) 
Table S2: Number of respondents and their country of residence. In total, 107 respondents from 23 countries participated in the survey.

\begin{tabular}{|c|c|}
\hline COUNTRY & RESPONDENTS (\%) \\
\hline AUSTRIA & $3.13 \%$ \\
\hline BELGIUM & $5.21 \%$ \\
\hline BOSNIA AND HERZEGOVINA & $1.04 \%$ \\
\hline CZECH REPUBLIC & $9.38 \%$ \\
\hline FRANCE & $21.88 \%$ \\
\hline GABON & $1.04 \%$ \\
\hline GERMANY & $19.79 \%$ \\
\hline GREECE & $2.08 \%$ \\
\hline HUNGARY & $2.08 \%$ \\
\hline IRELAND & $1.04 \%$ \\
\hline KOREA, SOUTH & $6.25 \%$ \\
\hline MACEDONIA & $2.08 \%$ \\
\hline MALAYSIA & $1.04 \%$ \\
\hline POLAND & $1.04 \%$ \\
\hline PORTUGAL & $4.17 \%$ \\
\hline SERBIA & $1.04 \%$ \\
\hline SPAIN & $3.13 \%$ \\
\hline SWEDEN & $5.21 \%$ \\
\hline SWITZERLAND & $4.17 \%$ \\
\hline TAIWAN & $1.04 \%$ \\
\hline TURKEY & $2.08 \%$ \\
\hline UNITED KINGDOM & $1.04 \%$ \\
\hline UNITED STATES & $1.04 \%$ \\
\hline
\end{tabular}


Table S3: Specific responses to the question: "What do you consider as the barriers to implementing more non-invasive research methods in ecological studies?"

\section{ID OTHER (PLEASE SPECIFY)}

\begin{tabular}{l|l}
\hline 1 & The research question
\end{tabular}

2 lack of time to check out alternative methods - it's often easier to use what has been use before...

3 We use standard methods that are difficult to replace

$4 \quad$ N.-i. methods for fish in running water e.g. eDNA not very developed

5 non-invasive methods not necessary, e.g. when only trapping animals for later release

6 Sometimes individuals need to be captured and measured, that is per se invasive

7 not applicable for experiments on insect development

8 the question does not apply: tiny insects must be killed for identification, birds must be caught for ringing

9 Jurisdiction, law, law enforcement

10 It sure depends on what kind of animals you are working on

11 Invertebrate determination not possible non-invasive

12 lack of appropriate methods

13 when working with insects $1-5 \mathrm{~mm}$ in size, these methods are simply not applicable

14 catching, identifying (as detailed as possible) and releasing invertebrates is a lot of effort and is very time limited - this reduces the number of sites and traps you can work with during a certain time period significantly. If time of day or day of the year vary too much, comparisons between sites become impossible. Animals caught alive can attack and eat each other, and they have only little energy reserves - so time in trap should be as short as possible.

I do not know about the barriers, we use non-invesive research methods.

I work on wild animals: stress is much less documented/investigated than for lab animals, what impairs easy and regular assessment of invasiveness (i.e. the level of stress induced, and its indirect consequences)

no real barriers

18 a lack of respect for animal life and nature in general

19 For our research we need to euthanize small mammals

20 Lazyness to find other ways to do it (the case of my current lab only)

21 I think that most non-invasive methods I have seen do not really offer viable alternatives to existing methods.

I worked as a field assistant so I did not design our experiments. Certain invasive methods are simply necessary (such as ear tagging individuals) while alternatives are possible for others.

The constrains related to the study of physiological mechanisms that may need tissue sampling

Non-invasive is used whenever but genomics data usually requite high amounf of DNA so blood or tissue are the only way worth it (feathers could be used for microsatts). There is no point taking a feather if the data out of it is not worth sampling an individual In some cases non-invasive research methods do not exist (yet)

many of those techniques are indirect indicators of what we want to measure and therefore less accurate. I prefer to use an invasive technique on a small number of animals, but have a clear answer to my scientific questions

We study fish (migration) behaviour in rivers. Visual observation is no option. We make use of mark (fin clip, floy tag, VIE tag, ...) and recapture methods and telemetry (radio-, PIT- and acoustic) methods.

31 I am not aware of any, I just do research that cannot be done without killing the studied invertebrates.

32 I generally think researcers are very conservative-minded and dont want to change previous protocols, even if less invasive ones are available 